\title{
A Conceptual Framework for Analysing Teaching Difficulties in the Science Classroom
}

\author{
Awelani V. Mudau \\ Department of Science and Technology Education, \\ University of South africa, South Africa \\ mudauav@unisa.ac.za
}

\author{
Doi:10.5901/mjss.2013.v4n13p125
}

\begin{abstract}
The purpose of this paper was to present a conceptual framework for analysing teaching difficulties in the science classroom. The framework was developed to assist and enhance diagnoses of teaching difficulties for the topic projectile motion and was thereof called the classroom practice diagnostic framework (CPDF). Data from two cases in the Johannesburg central district in South Africa was collected using interviews as well as observations of lessons in the topic projectile motion. Data was organised into themes and categories which were then analysed based on the CPDF to diagnose teaching difficulties. Based on the outcomes we can conclude that the CPDF has merit as an effective tool to analyse classroom practices and subsequently diagnose teaching difficulties. In addition the CPD framework may assist with information to assist in professional training of in-service teachers.
\end{abstract}

Keywords: Framework, Science classroom, Teacher practice, teaching difficulties

\section{Introduction}

Where there is a perception of teaching difficulties which hampers meaningful learning it is our duty to find ways of identifying those teaching difficulties to influence meaningful learning of science positively. Studies and experiences in science teaching have shown that teachers can perceive some topics of the science curriculum as difficult to teach (Gunstone et al., 2008; Tao and Gunstone, 1999). Teaching difficulty is not something easy to articulate (Geelan et al., 2004). Due to the nature of the subject, difficulty in teaching can happen when teachers fail to make their classroom practices assist them to achieve the end. In science teaching the end refers to achievements by students, meaningful learning, developing inquiry skills and problem solving skills in students (Abd-El-Khalick and Akerson, 2009).

Therefore, the purpose of this study was to present the classroom practice diagnostic framework (CPDF) as an alternative diagnostic tool for science classroom analysis and also show how it was used to diagnose teaching difficulties of the projectile motion topic. The framework may assist with information to assist in professional training of in-service teachers. We say this because it should add into the resources of micro foundation for in-service support because there is impervious lack of micro foundation resources (Jita, 2004). The following questions guided this paper; 1 . What is the CPDF? 2. How was the CPDF applied?

\section{Developing the CPDF}

According to Maxwell (2005:33), the conceptual framework is "the systems of concepts, assumptions, expectations, beliefs and theories that support and inform your research". Furthermore, it is something that one builds from pieces borrowed elsewhere and so it is not something that is readymade (Maxwell, 2005). These assumptions were taken into consideration when developing the CPDF.

A theoretical and conceptual framework that would assist in investigating the teaching of projectile motion with a focus on teacher knowledge, instructional strategies and the interactions and discourse in the teacher's classroom was required. Consequently, the constructivism theory was adopted as the underpinning theory of the framework.

Constructivism informs teacher practice (Hausfather, 2001); it is not a method of teaching but a theory of knowledge and learning, thus the emphasis is on the teaching context, student prior knowledge and interaction between the student and the content. Tobin and Fraser (1998) indicate that constructivism is to be used as a base for thoughts and actions by teachers. Consequently, Leach and Scott (2003: 102) typify the role of the teacher within constructivism as "to introduce and support the use of new knowledge on the social plane", whilst the role of the student is to "internalise 
the ideas for personal use". Furthermore, according to Hausfather (2001) the "amount" of teacher's content knowledge within constructivism theory is important for the development of understanding in students. He further indicates that the teacher supports the use of the new knowledge by creating situations wherein students interact with information, using it to solve problems, discussing interpretations and answering questions as it becomes their own. However, this requires the continuous restructuring of the subject matter knowledge by the teacher which Cochran, DeRuiter and King (1993) term pedagogical content knowing.

There are various forms of constructivist theories (Hausfather, 2001; Mathews, 1995 and Geelan, 1997), some of which are personal, radical, social, critical and contextual. According to Geelan (1997), these forms of constructivism can be organised into those that are social and those that are personal. They can further be classified as objectivist or relativist (Mathews, 1995), for example the social and critical constructivist theories. However, according to Leach and Scott (2003) these many forms of constructivism can be simply classified as two broad strands of the constructivist theories of teaching and learning which are based on individual views and on sociocultural learning.

The individual view (Piagetian) focuses on the mental structure of the student (Leach \& Scott, 2003; Nola, 1997 and Piaget, 1964). The sociocultural view integrates both the individual view and the social environment (Vygotskian). In this perspective learning takes place in a social milieu as well as in the mental structure of the individual (Kim, 2001; Lemke, 2001; Davydov, 1995 and Vygotsky, 1978). This point was also raised by Carr et al. (1994), who regarded science as a human and social construct and posited that learning is a personal construct which is influenced by the social context. Hausfather (2001:15) also indicates that social constructivism "proposes that knowledge emerges from human activity as people interact with each other and with the physical world using their minds and bodies as well as material and symbolic tools made available to them by their culture". So in developing the CPDF the social constructivism was used which takes into account the social context.

With the social constructivism theory as the overarching and underpinning theory for the framework, some PCK models were also adopted which would enable the researcher to focus on the specific classroom practice aspects of the teacher such as teacher knowledge as well as the kinds of instructional strategies he/she used in the classroom. PCK models were chosen because they make it possible to target certain aspects of teacher knowledge (Rollnick et al., 2008). The models that appealed to the aims of this framework are models by Rollnick et al. (2008) and Magnusson et al. (1999). In the latter model, more emphasis is on the knowledge and beliefs of the teacher, whilst in the model proposed by Rollnick et al. (2008) the emphasis is on the observations of the domains of the teacher knowledge from the teacher's practice.

PCK is the knowledge that includes "an understanding of what makes the learning of a specific topic easy or difficult" (Shulman, 1986:9). This is the knowledge that encompasses the understanding of preconceptions of students. Teachers then need knowledge of the strategies that will reorganise the understanding of students. PCK is a skill and knowledge which is realised when the teacher accesses what he or she knows in terms of curriculum, student understanding, subject matter, pedagogic principles and all this embedded in his/her experiences. So it is not only about the knowledge of various domains which amalgamate to result in the PCK, but the teacher's craft is the ultimate variable in the classroom practice for students' learning. This is also a claim by Lee and Luft (2008), who indicate that PCK is the experiential knowledge and skills acquired through experience in the classroom.

Within social constructivist theory, the interactions between the student and the teacher, the students themselves and the social milieu are the fundamental basis for knowledge construction by students (Leach \& Scott, 2003). Furthermore, the discourse used to facilitate meaningful learning by the teacher is also fundamental. This was why the analytical framework for analysing science teaching interactions by Mortimer and Scott (2003) was considered in the development of the framework.

It follows then that from the PCK models (Rollnick et al., 2008 and Magnusson et al., 1999) and the analytical framework for analysing science teacher interactions (Mortimer \& Scott, 2003) within social constructivist theory a classroom practice diagnostic framework (CPDF) was developed. As the focus was on teacher knowledge and instructional strategies from the PCK model of Rollnick et al. (2008), the domain of teacher knowledge which informs the instructional strategies was used to develop the CPDF. However, the model by Rollnick et al. (2008) was not explicit in terms of knowledge of areas of students' difficulties, whereas the model of Magnusson et al. (1999) was explicit; hence the two models were integrated. The focus of the study was also on classroom interactions and discourse wherein teacher knowledge and instructional strategies are made explicit. Therefore, from the analytical framework for analysing science teacher interactions (Mortimer \& Scott, 2003), the aspects of communicative approach and patterns of discourse were considered for the CPDF. The framework was called CPDF as it is used as the frame of reference from which teaching difficulties were diagnosed. 


\section{The Classroom Practice Diagnostic Framework}

In this section, what the CPDF entails is described.

Figure 1: The Classroom Practice Diagnostic Framework (CPDF)

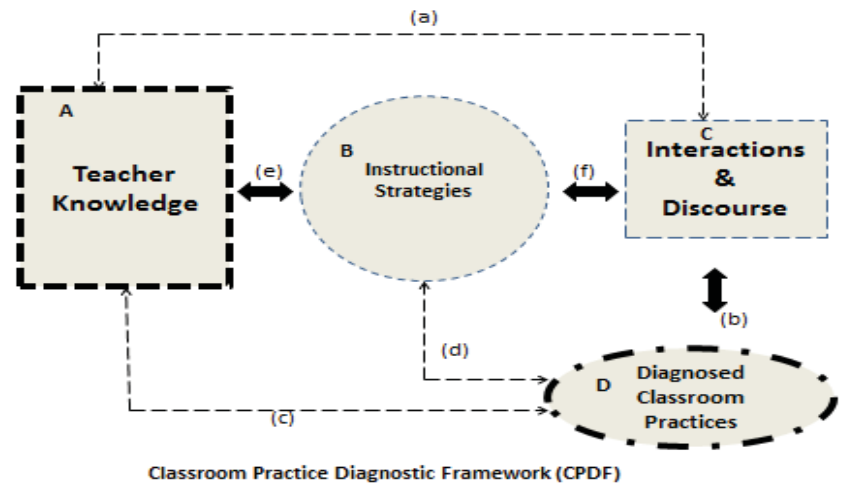

In the CPDF there are four main domains ( $A, B, C$ and $D)$. Hierarchically, frame $A$ occupies an important place for the understanding of the teacher's practice. That is, it is the source and it influences every action of the teacher as it contains the important knowledge in respect of teaching. Teacher knowledge is made up of content, context and students' understanding knowledge. Frame B is informed by the teacher's knowledge. The teacher uses his or her knowledge to decide on instructional strategies. The instructional strategies are made up of epistemological perspectives, traditional teaching methods, explanatory frameworks and activities. His/her strategies lead to the interactions and discourse in the classroom. In the classroom interaction and discourse frame; the emphasis was on the types and patterns of discourse, communicative approach and teacher questioning. Types of discourses comprised the authoritative, dialogic and reflective discourses. Some of the actions or activities are spontaneous [this part is accommodated in the link (a) between $A$ and $C$ ]. Frame $C$ is the culmination of the interactions of frames $A$ and $B$. The analysis or diagnosis focuses mainly on what happens in this frame or outcome. The outcomes of the analysis are however in all the frames, both in their interaction or individually. The frames can be related with links [(a), (b), (c), (d), (e) and (f)] to get to the bottom of the teacher's classroom practices.

In the teacher knowledge frame, the content knowledge is what and how well the teacher knows the subject matter and its organisation (Kind, 2009 and Hausfather, 2001). How well the teacher knows the subject matter is informed by Shulman's (1987:14) notion that "to teach is first to understand". Organisation of the subject matter refers to the sequencing of concepts in a topic. Students' understanding knowledge is the teacher's knowledge of the prior knowledge, linguistic abilities, and interests of the students as well as their misconceptions. Context knowledge is all the contextual aspects that could influence the teaching of the subject matter such as resources, socio-economic background and the curriculum.

The instructional strategies are made up of epistemological perspectives, traditional teaching methods, explanatory frameworks and activities. An epistemological perspective is how a teacher demonstrated through practice how knowledge is acquired. Traditional teaching methods are methods like lecturing and demonstration methods which the teacher used. Explanatory frameworks are the analogies, models and/or illustrations the teacher used to make the learning of projectile motion accessible to students. Activities imply problems, demonstrations, simulations, investigations or experiments which the teacher used to help students comprehend the content.

In the classroom interaction and discourse frame; the emphasis was on the types and patterns of discourse, communicative approach and teacher questioning. Types of discourses comprised the authoritative, dialogic and reflective discourses. Patterns of discourse represented the initiations of the teacher as well as the feedback he/she provided, for example the IRF (initiation, response and feedback) pattern. In the communicative approach four classes of communicative discourse were focused on, namely interactive-authoritative, non-interactive-authoritative, interactivedialogic and non-interactive-dialogic. Teacher questioning focused on the teacher's orientation when asking questions. 


\section{The Application of the Framework}

The CPDF was used in diagnosing the classroom practices of the teacher, that is, the means (Staver, 2007) such as teacher knowledge, instructional strategies and interactions and discourse that were regarded as not helping the teacher to promote the end. The end was meaning making, misconception dissonance, the development of inquiry and problem solving skills, all of which influence the achievements of students (Abd-El-Khalick \& Akerson, 2009).

The teacher is expected to know the common misconceptions and experiences of students and their prior knowledge so that s/he can introduce the new subject matter from those constructs for students to learn the new subject matter (Eryilmaz 2002; Galus, 2002 and Hausfather, 2001). Therefore, the framework was used as a frame of reference to establish whether the teacher was aware of the common misconceptions regarding the topic and, if so, how s/he used instructional strategies as well as the nature of the interactions and discourse to create misconception dissonance if they manifested during teaching. Moreover, the assertions that misconceptions may be created and/or introduced (Graham et al., 2012; Bayraktar, 2009; Prescott \& Mitchelmore, 2005 and Prescott, 2004) during teaching by the teacher or students were also considered. So, it was not only about diagnosing the awareness but also finding out whether the teacher did have misconceptions which could be transferred to the students or if the teacher created or introduced misconceptions during teaching.

The framework was further used to diagnose how the teacher supported the meaning making process (Leach \& Scott, 2003 and Mortimer \& Scott, 2003). The focus was on the kind of the communicative approach and discourse the teacher used in the social plane wherein s/he introduced the new subject matter knowledge. This was based on the notion that knowledge is constructed during social interaction (Carr et al., 2004; Lemke, 2001; Kim, 2001 and Davydov, 1995). Furthermore, the framework was used as a basis to diagnose how the teacher used instructional strategies and classroom interactions and discourse to facilitate internalisation of the subject matter knowledge by the students. This was so because according to Vygotsky (1978: 128) "the process of internalisation is where individuals appropriate and become able to use for themselves conceptual tools first encountered on the social plane". So it is the role of the students to internalise the new knowledge (Leach \& Scott, 2003) and for teachers to support the process. How the teacher uses prior knowledge also influences internalisation of the subject matter because according to Hausfather (2001) learning involves continuous connection between the prior knowledge and the new subject matter.

The final phase in the process of meaning making is the application phase. So the framework was used as the reference point to diagnose the kinds of instructional strategies, interactions and discourse the teacher used to create opportunities for students to answer questions, solve problems and discuss the knowledge (Hausfather, 2001) to reinforce knowledge development. This was so because according to Nola (1997: 59) "only when they can go through the steps of reasoning by themselves and thereby make fully explicit to themselves the reasons for the answer will they have knowledge". The framework was also used to diagnose the kinds of instructional strategies and the interactions and discourse the teacher used to promote the development of inquiry and problem solving skills. For example, if the explanatory framework of the teacher is based on examples or the teaching methods entail largely question and answer and lecture, problem solving and inquiry skills may not be developed. This is so because those strategies do not promote reasoning and thinking ability (Nola, 1997), both of which are fundamental for the development of inquiry and problem solving skills (Abd-El-Khalick \& Akerson, 2009).

\section{Methodology}

Two cases Mr. Z and Ms. Q perceived projectile motion to be difficult to teach and were qualified to teach Physical Science at their respective schools. Both had more than 10 years' experience of teaching Physical Science. Data was collected through interviews and lessons observations. They were interviewed before the teaching of the projectile motion topic. Then they were observed whilst teaching the topic. They were again interviewed after teaching the topic. The CPDF was used in diagnosing the classroom practices of each teacher for teaching difficulties. We read the data with the framework in mind and identified relevant data which we organised using the table which had themes form domain $\mathrm{A}, \mathrm{B}$ and $\mathrm{C}$ of the CPDF.

To identify a teaching difficulty we applied the CPDF by considering, the framework as frame of reference to establish if the teacher was aware of the common misconceptions in the topic and if he/she was aware how he/she used instructional strategies as well as the nature of the interactions and discourse to create misconceptions dissonance if they manifested during teaching. However, it was not only diagnosing the awareness but also if the teacher does have misconceptions which can be transferred to the students or if the teacher creates or introduces misconceptions during 
teaching. The framework was also used to diagnose how the teacher supported the meaning making process of the concepts of the topic projectile. The focus was on the kind of the communicative approach and discourse the teacher used in the social plane wherein he/she introduced the new subject matter knowledge. Furthermore, the framework was used as a basis to diagnose how the teacher used instructional strategies and classroom interactions and discourse to facilitate internalization of the subject matter knowledge by the students. The framework was also used as the reference point to diagnose the kinds of instructional strategies, interactions and discourse the teacher used to create opportunities for students to answer questions, solve problems and discuss the knowledge to reinforce knowledge development. The framework was also used to diagnose the kinds of instructional strategies and the interactions and discourse the teacher used to promote the development of inquiry and problem solving skills

\section{Examples of teaching difficulties identified using the CPDF.}

\subsection{Case $1(\mathrm{Mr}$ Z)}

Various teaching difficulties were identified from Mr Z's classroom practices using the CPDF. For example Instructional strategies and discourse did not promote students' thinking and reasoning, a fundamental for the development of inquiry and problem solving skills.

The teacher used illustrations and examples as his explanatory framework and problems as teaching activities for the lessons. According to Magnusson et al. (1999) explanatory frameworks and activities should be used by the teacher to help students to comprehend the subject matter knowledge. Hollon et al. (1991) also indicate that instructional strategies should engage students such that they are able to think and also realise that their thinking is important. However, the teacher was focused on providing students with examples so that they could learn through experience without reasoning. Yet, the nature of the subject matter is such that it is loaded with abstract concepts (Gunstone et al., 2009 and Schwartz \& Lederman, 2008), for example forces, and it demands appropriate explanatory frameworks for students to comprehend such concepts. Furthermore, the kind and pattern of the discourse which was IRF and authoritative in an interactive-authoritative communicative style did not promote debate and learning by negotiation.

During interviews the teacher had indicated the intention to also use experiments in his teaching. Mr Z indicated that:

If something that involves like in the mechanics part then learners (students) must be taken out of that environment of the class and get outside and investigate some of the things and come back and see if it makes sense

In practice the teacher used traditional teaching methods, for example demonstrations, lecturing and questions and answers. According to Schwartz and Lederman (2008), traditional methods of transmitting information such as those which Mr Z used do not help students comprehend abstract concepts. Figure 2 illustrates the instructional strategies and classroom discourse for $\mathrm{Mr} \mathrm{Z}$.

Figure 2: Mr Z's instructional strategies and discourse

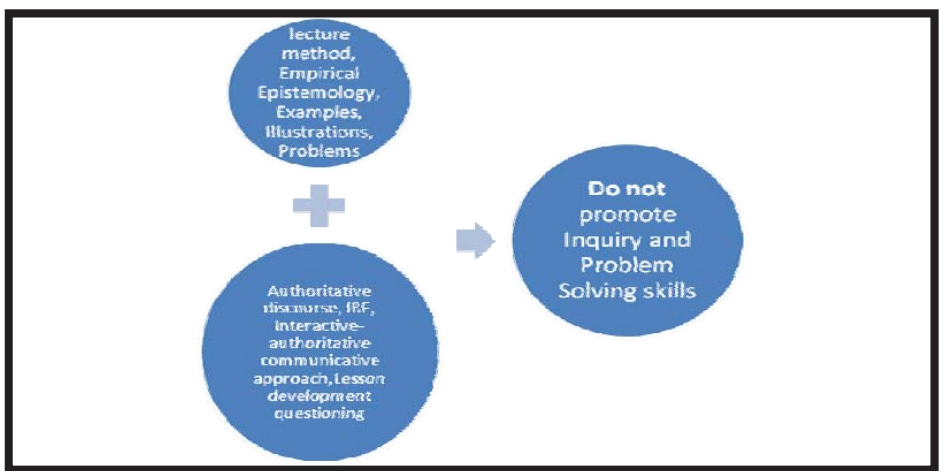

As illustrated in Figure 2 the instructional strategies the teacher used and the classroom discourse in the teaching of 
projectile motion did not create opportunities for students to think and reason. The instructional strategies, interactions and discourse the teacher used reflect him as a teacher who is operating within level one from Biggs' (2001) three levels of teaching theories. Mr Z's presentation of the lesson was teacher centred and he was transmitting the knowledge of the projectile motion topic to the students. He did not align the instructional strategies, interactions and discourse such that students could develop the kinds of understanding and skills necessary for the topic of projectile motion.

According to Nola (1997), students do not acquire knowledge without thinking and reasoning about the concepts themselves; they need opportunities to reason and construct understanding. In addition, Hausfather (2001) indicates that knowledge emerges from an interaction by people with one another. Furthermore, Hausfather (2001) points out that the teacher is expected to create and support the learning process by creating situations wherein students interact with information and use it to solve problems and answer questions. With the kinds of instructional strategies, interactions and discourse this teacher used the learning process was not supported.

In conclusion, it follows that the instructional strategies, interactions and discourse employed by Mr Z make a good example of why students do not have problem solving and inquiry skills, as indicated by the Department of Basic Education (DBE, 2011a). According to Akarsu (2010); Akerson and Donnelly (2010) as well as Abd-E- Khalick and Akerson (2009), problem solving and inquiry skills develop when students think and reason about scientific concepts. The DBE (2010 and 2011a) examines students on inquiry and problem solving skills in projectile motion. So students may not respond correctly to some of the questions on the topic of projectile motion even after the teacher has taught them. This may be so because students have not developed the required problem solving and inquiry skills. Consequently, some teaching difficulties may result from the nature and types of instructional strategies and classroom discourse used by the teacher.

The teaching difficulty presented above was identified after an integration of aspects such as instructional strategies, interactions and discourse used in the classroom by teacher A. We analysed the aspects at a micro level. We could not have identified how the integration of aspects indicated, can cause a teaching difficulty, if we did not have a closer diagnose of the teacher's practise through the CPDF.

\subsection{Case $2(M s Q)$}

Teaching difficulties were identified from Ms Q's classroom practices using the CPDF, for example pre-Newtonian teaching of projectile motion in two dimensions. Aristotelian theorists did not understand projectile motion and even during the impetus theory period it was still misunderstood. It was not until the times of Galileo and Newton that it was better understood (Gilbert and Zylbersztajn, 1985). It is therefore remarkable to note what happened in Ms Q's class in teaching projectile motion in two dimensions in terms of the history of the concept of projectile motion. She correctly made use of an example to teach the topic. However, she did not teach about the force involved nor show the difference between projectile motion in two dimensions and horizontal and vertical motions. This was important for meaningful learning by students (Galus, 2002).

She simply showed students how to solve the problem using trigonometrical ratios as well as the Pythagoras theorem. Moreover, the activity was teacher centred and not student centred (Biggs, 2001). This is so because she did all the work on the chalkboard with students intermittently being involved here and there. It was not a coordinated effort by the teacher to involve students in the lesson. She did not create opportunities for students to consider why they had to solve problems in projectile motion by using trigonometrical ratios or/and the Pythagoras theorem. Ms Q simply said "when they see 'degrees' they must know that they are dealing with projectile motion in two dimensions". This was very simplistic and promoted memorisation as students might end up looking only look for "degrees" and, if there were none; conclude that they were not dealing with two dimensions. Hence, it was inferred that the teacher demonstrated Aristotelian or impetus theoretical perspectives which are pre-Newtonian perspectives.

According to Gess-Newsome (1999), the knowledgeable teacher involves students actively in the lesson whilst the unknowledgeable teacher's teaching style is algorithmic, s/he tends to teach such that only questions that are up to the students' current level are asked, and is dismissive of alternative answers. Ms Q presented this section as an unknowledgeable teacher. Hence, this could be the reason why she did not create opportunities for discussions in the classroom. The approach the teacher used did not create an atmosphere wherein students would interact with the new subject matter to construct understanding (Nola, 1997). There was no interaction between the teacher and the students or amongst the students themselves to promote discussion (Hausfather, 2001). It follows that Ms Q's students may not make meaningful learning of projectile motion in two dimensions. Furthermore, if one considers Starver's (2007) view that one of the purposes of science teaching is to prepare students to study science at higher education institutions, Ms Q's 
students will be compromised as they may be ill prepared in terms of projectile motion in two dimensions.

Ms Q's teaching difficulty was diagnosed based on one aspect of the CPDF which is the teacher knowledge and in particular the students' understanding knowledge. Hence, the CPDF assisted in focusing on a particular aspect to diagnose the teaching difficulty. However the diagnosis is at a micro level that is we had to look closely at how the teacher understood prior knowledge required for the learning of projectile motion. We also focused on how Ms. Q used or not used prior knowledge.

\section{Conclusion}

It was the purpose of this paper to expatiate on what the CPDF is, as well as show how it was used to diagnose teaching difficulties. So we showed from the two cases that the CPDF can assist to diagnose a teaching difficulty from an integration of aspects such as instructional strategies, interactions and discourse. We also showed that the CPDF can assist in diagnosing a teaching difficulty from one aspect such as teacher knowledge of students' understanding and how it is used or not used during classroom practice. The other frameworks would not have assisted in achieving this. How the framework was applied to determine teaching difficulties should add into the debate on teacher practices in science teaching. We also envisage that the framework can be used as a fundamental resource for in-service training to identify the teacher's areas of development in their practices. The framework may also assist to derive a picture of how different facets of teacher practices can generate teaching difficulty which should make it possible to provide tailored intervention either be content knowledge, context knowledge, instructional strategies or nature of discourse if a deficiency was diagnosed. We also concede that the framework has not been tested at a large scale and other topics. So we suggest further research on a large scale and other topics perceived to be difficult to teach.

\section{References}

Abd-El-Khalick, F. and Akerson, V. (2009). The influence of metacognitive training on preservice elementary teachers' conceptions of nature of science. International Journal of Science Education, 31(16), 2161-2184.

Akarsu, B. (2010). The influence of disciplines on the knowledge of science: a study of the nature of science. Bulgarian Journal of Science and Education Policy, 4(1), 99-118.

Akerson, V. and Donnelly, L.A. (2010). Teaching nature of science to K-2 students: What understanding can they claim? International Journal of Science Education, 32(1), 97-124.

Bayraktar, S. (2009). Misconceptions of Turkish pre-service teachers about force and motion. International Journal of Science and Mathematics Education, 7, 273-291.

Biggs, J. (2001). The reflective institution: assuring and enhancing the quality of teaching and learning. Higher Education, 41, 221-238.

Carr, M., Barker, M., Beverley, B., Biddulph, B., Jones, A., Kirkwood, V., Pearson, J. and Symington, D. (1994). The constructivist paradigm and some implications for science content and pedagogy. In: P. Fensham, R. Gunstone, and R. White. The content of science: a constructivist approach to its teaching and learning. London: Falmer Press, pp. 147-158.

Cochran, K.F., DeRuiter, J.A. and King, R.A. (1993). Pedagogical content knowing: an integrative model for teacher preparation. Journal of Teacher Education, 44(4), 263-272.

Davydov, V.V. (1995). The influence of L.S. Vygotsky on education theory, research and practice. Educational Researcher, 24(3), 12-21.

Department of Basic Education. (2009). Report of the task team for the review of the implementation of the National Curriculum Statement. Pretoria: Department of Basic Education.

Department of Basic Education. (2010). Road show reports. Pretoria: Department of Basic Education.

Department of Basic Education. (2011a). Report on the National Senior Certificate examination results. Pretoria: Department of Basic Education.

Department of Basic Education. (2011b). National diagnostic reports on learner performance. Pretoria: Department of Basic Education.

Department of Basic Education. (2011c). School performance analysis. Pretoria: Department of Basic Education.

Department of Education. (2006). National policy framework for teacher education and development in South Africa. Pretoria: Department of Education.

Department of Education. (2007). National Curriculum Statement Grades 10-12 Subject Assessment Guidelines Physical Sciences. Pretoria: Department of Education.

Eryilmaz, A. (2002). Effects of conceptual assignments and conceptual change discussion on students' misconceptions and achievement regarding forces and motion. Journal of Research in Science Teaching, 39(10), 1001-1015.

Galus, P.J. (2002). Toying with motion. The Physics Teacher, 69(4), 48-51.

Geelan, D.R. (1997). Epistemological anarchy and the many forms of constructivism. Science and Education, 6(2), 15-28.

Geelan, D.R., Wildy, H., Louden, W. and Wallace, J. (2004). Teaching for understanding and/or teaching for the examination in high school physics. International Journal of Science Education, 26(4), 447-462.

Gess-Newsome, J. (1999). Pedagogical content knowledge: an introduction and orientation. In: J. Gess-Newsome \& N.G. Lederman 
eds. Examining pedagogical content knowledge: the construct and its implications for science education. Dordrecht: Kluwer, pp. 3-17.

Gilbert, H.K. and Zylbersztajn, A. (1985). A conceptual framework for science education: the case study of force and movement. European Journal of Science Education, 7(2), 107-120.

Graham, T., Berry, J. and Rowlands, S. (2012). Are 'misconceptions' or alternative frameworks of force and motion spontaneous or formed prior to instruction? International Journal of Mathematical Education in Science and Technology, (24 July 2012), 1-20.

Gunstone, R., Mulhall, P. and McKittrick, B. (2009). Physics teachers' perceptions of the difficulty of teaching electricity. Research in Science Education, (39), 515-538.

Hausfather, S. (2001). Where's the content? The role of content in constructivist teacher education. Educational Horizons, 79(1), $15-19$.

Hollon, R.E., Roth, K.J. and Anderson, C.W. (1991). Science teachers' conceptions of teaching and learning. Advances in Research on Teaching, (2), 154-185.

Jita, L.C. (2004). Resources of biography: teacher identities and science teaching. Perspectives in Education, 22(4), 11-27.

Kim, B. (2001). Social constructivism. Emerging perspectives on learning, teaching and technology. [Online] Available: http://www.coe.uga.edu/epltt/socialConstructivism.html [Accessed 10 October 2012].

Kind, V. (2009). Pedagogical content knowledge in science education: perspectives and potential for progress. Studies in Science Education, 45(2), 169-204.

Leach, J. and Scott, P. (2003). Individual and sociocultural views of learning in science education. Science \& Education, 12(1), 91-113.

Lederman, N.G (1992). Students' and teachers' conceptions about the nature of science: a review of the research. Journal of Research in Science Teaching, 29, 331-359.

Lee, E. and Luft, J.A. (2008). Experienced secondary science teachers' representation of pedagogical content knowledge. International Journal of Science Education, 30(10), 1-34.

Lemke, J.L. (2001). Articulating communities: sociocultural perspectives on science education. Journal of Research in Science Teaching. 38(3), 296-316.

Magnusson, S., Krajcik, J. and Borko, H. (1999). In: J. Gess-Newsome and N.G. Lederman, eds. Nature, sources and development of pedagogical content knowledge. Examining pedagogical content knowledge: the construct and its implications for science education.Dordrecht: Kluwer Academic Publishers, pp. 95-132.

Mathews, M.R. (1995). Challenging NZ science education. Palmerston North: Dunmore Press.

Maxwell, J.A. (2005). Qualitative research design: an interactive approach. $2^{\text {nd }}$ ed. Thousand Oaks, CA: Sage Publications.

Mortimer, E.F. and Scott, P.H. (2003). Meaning making in secondary science classrooms. Maidenhead: Open University Press.

Nola, R. (1997). Constructivism in science and science education: a philosophical critique. Science and Education, 6, 55-83.

Piaget, J. (1964). Development and learning. Journal of Research in Science Teaching, 2(3), 176-186.

Prescott, A. and Mitchelmore, M. (2005) Teaching projectile motion to eliminate misconceptions. In: H.L. Chick, and J.L. Vincent, eds. Proceedings of the $2^{\text {th }}$ Conference of the International Group for the Psychology of Mathematics Education, 4, 97-104.

Prescott, A.E. (2004). Student understanding and learning about projectile motion in senior high school. Unpublished doctoral thesis. Macquarie University, Sydney.

Rollnick, M., Bennett, J., Dharsey, N. and Ndlovu, T. (2008). The place of subject matter knowledge in pedagogical content: a case study of South African teachers teaching the amount of substance and chemical equilibrium. International Journal of Science Education, 30(10), 1365-1387.

Schwartz, R. and Lederman, N. (2008). What scientists say: scientists' views of nature of science and relation to science context. International Journal of Science Education, 30(6), 727-771.

Shulman, L.S. (1986). Those who understand: knowledge growth in teaching. Educational Researcher, 15(2), 4-14.

Shulman, L.S. (1987). Knowledge and teaching: foundations of the new reform. Harvard Educational Review, 57(1), 1-22.

Staver, J.R. (2007). Teaching science. Geneva: Educational Practices Series, The International Academy of Education (IAE) and the International Bureau of Education (UNESCO).

Tao, G. and Gunstone, R.F. (1999). The process of conceptual change in force and motion during computer-supported physics instruction. Journal of Research in Science Teaching, 36(7), 859-882.

Tobin, K. and Fraser, B.J. (1998). Qualitative and quantitative landscapes of classroom learning environments. In B.J. Fraser \& K G. Tobin (Eds.), International handbook of science education (623-640). Dordrecht, The Netherlands: Kluwer.

Vygotsky, L.S. (1978). Mind in society: the development of higher psychological processes. Cambridge, MA: Harvard University press. 